Proceeding Series of the Brazilian Society of Computational and Applied Mathematics

\title{
Elaboração de Material Didático para Promover o Ensino de Matemática e Estatística no Ensino Fundamental
}

\section{Clara Augusta Marques Natalin ${ }^{1}$}

Graduanda em Engenharia Agronômica, UNESP, Jaboticabal, SP.

$$
\text { Amanda Liz Pacífico Manfrim Perticarrari }{ }^{2}
$$

Andreia da Silva Meyer ${ }^{3}$

Nelson José Peruzzi ${ }^{4}$

Departamento Ciências Exatas, UNESP, Jaboticabal, SP.

\author{
Aline Maria Pacífico Manfrim 5 \\ Instituto Federal de São Paulo, IFSP, Araraquara, SP.
}

\begin{abstract}
Resumo. O presente trabalho visa desenvolver um material didático para promover o ensino de matemática e estatística aos discentes do Ensino Fundamental através de uma metodologia de ensino e aprendizagem pautada em questões relacionadas ao cotidiano deste público, a qual identifica situações-problema a serem exploradas. Estes dados foram tabulados e uma análise descritiva resumiu as informações das respostas obtidas por meio do questionário.
\end{abstract}

Palavras-chave. Educação matemática e estatística, Questionário aplicado, Material didático.

\section{Introdução}

As informações matemáticas e estatísticas sempre estiveram presentes na vida dos cidadãos e, assim como muitas pessoas confiam e utilizam para nortear suas decisões, outras desconfiam e/ou atacam sua verossimilhança [2]. No final da década de 90, os conceitos básicos de matemática e estatística, antes quase ignorados na Educação Básica, passaram a ser discutidos pela comunidade educacional e acadêmica, tendo sido incorporados oficialmente à estrutura curricular da disciplina de Matemática do Ensino Fundamental (EF) e Ensino Médio (EM) com a publicação dos Parâmetros Curriculares Nacionais - PCNs, veja [1] e [3].

Os PCNs sugerem aos professores que incentivem os alunos a observar os fenômenos,

1 claranatalin@hotmail.com

2 amanda@fcav.unesp.br

3 andreiameyer@fcav.unesp.br

${ }^{4}$ peruzzi@fcav.unesp.br

5 a_manfrim@yahoo.com 
conjeturar hipóteses, fazer levantamento de dados, tratá-los e analisá-los do ponto de vista da investigação científica. Também incentivam a leitura e a interpretação de gráficos, de tabelas e de medidas publicadas pelos diversos meios de comunicação, a fim de que o aluno saiba posicionar-se de forma crítica diante dessas informações e lhes fornecer ferramentas para arguir e "desmantelar" informações porventura falaciosas ou mal-intencionadas [3].

Ao ensino de Matemática, fica o compromisso de não só ensinar o domínio dos números, mas também a organização de dados e a leitura de gráficos. Dessa forma, o presente estudo visa elaborar um material didático contendo situações-problema, identificadas a partir de um questionário aplicado aos discentes do $\mathrm{EF}$ - abordando conhecimentos prévios e práticas do cotidiano desse público - para a promoção do ensino de matemática e estatística.

\section{Material e Método}

Este trabalho faz parte de um projeto do Núcleo de Ensino/PROGRAD da UNESP intitulado "Alfabetização Estatística" que está sendo realizado pelo Departamento de Ciências Exatas da FCAV/UNESP com colaboração da Diretoria de Ensino do município de Jaboticabal/SP.

Foi elaborado um questionário, implementado no aplicativo Google Docs e disponibilizado aos alunos do EF no site da Diretoria de Ensino de Jaboticabal www.dejaboticabal.com.br, contendo questões de múltipla-escolha, visando detectar situações problema que fazem parte do cotidiano dos alunos do EF, para a criação e adaptação de material didático a ser utilizado com os alunos do $6^{\circ}$ ao $9^{\circ}$ ano deste período escolar, promovendo a educação de matemática e estatística a esse público.

As questões elaboradas foram baseadas em ambientes do cotidiano dos discentes. Cada tema continha cinco alternativas de (A) a (E). A coleta de dados foi realizada no primeiro bimestre de 2015 com os alunos do $6^{\circ}$ ao $9^{\circ}$ ano do EF das escolas Estaduais do município de Jaboticabal/SP.

\section{Conclusão}

Nesta etapa, ainda inicial do projeto, foi possível elaborar um questionário, implementá-lo no aplicativo Google Docs e disponibilizá-lo aos alunos do EF no site da Diretoria de Ensino de Jaboticabal. Este questionário priorizou verificar as situações-problema que fazem parte do cotidiano dos discentes do $6^{\circ}$ ao $9^{\circ}$ ano do EF, favorecendo a contextualização dos conteúdos abordados nas atividades desenvolvidas no material didático.

\section{Referências}

[1] Brasil. Secretaria de Educação Fundamental. Parâmetros Curriculares Nacionais: Matemática. Brasília: MEC/SEF, (1998).

[2] I. M. Cazorla e F. C. de Castro. O papel da estatística na leitura do mundo: o letramento estatístico. UEPG Humanit. Sci., Appl. Soc. Sci., Linguist., Lett. Arts, Ponta Grossa, 16 (1) 45-53, (2008).

[3] C. E. Lopes, C.Q. Coutinho e S. Almouloud. Estudos e reflexões em educação estatística. 1. Ed. Campinas: Ed. Mercado de Letras, (2010). 